\title{
Assessment of complications following use of pneumatic tourniquet for elective orthopedic procedures at National Orthopedic Hospital, Enugu
}

\author{
Remigius T. Ekwunife ${ }^{1 *}$, Emmanuel C. Iyidobi ${ }^{1}$ Ugochukwu M. Enweani $^{2}$, \\ Cajetan U. Nwadinigwe ${ }^{1}$, Charles I. Okwesili ${ }^{3}$, Henry C. Ekwedigwe ${ }^{4}$, Emmanuel O. Agbo ${ }^{1}$
}

\begin{abstract}
Department of Orthopedics, ${ }^{1}$ National Orthopedic Hospital, ${ }^{2}$ City Specialist Hospital, Enugu, Nigeria ${ }^{3}$ Department of Surgery, College of Medicine, University of Nigeria, Enugu Campus, Nigeria

${ }^{4}$ Department of Orthopedics, Enugu State University Teaching Hospital Parklane, Enugu, Nigeria
\end{abstract}

Received: 02 June 2019

Accepted: 05 July 2019

\section{*Correspondence:}

Dr. Remigius T. Ekwunife,

E-mail: remyclassic@yahoo.com

Copyright: (c) the author(s), publisher and licensee Medip Academy. This is an open-access article distributed under the terms of the Creative Commons Attribution Non-Commercial License, which permits unrestricted non-commercial use, distribution, and reproduction in any medium, provided the original work is properly cited.

\begin{abstract}
Background: A pneumatic tourniquet is a constricting or compressing device with an inflatable cuff used to control venous or arterial circulation to an extremity for a period of time. Tourniquet safety is related to the cuff pressure and duration of application. The objective of this study was to determine the common complications that follow the use of pneumatic tourniquet in elective orthopaedic surgical procedures at National Orthopaedic Hospital Enugu.

Methods: This was a prospective study over 18 month period (June 2014 - November 2015) at National Orthopaedic Hospital, Enugu. Following ethical approval and written informed consent, patients who met the inclusion criteria were consecutively recruited. The study was conducted using the 'intelligent pneumatic tourniquet' with single bladder reusable cylindrical cuff. The cuff pressure was determined in each case by addition of $100 \mathrm{mmHg}$ to the baseline systolic BP for the upper limbs and $150 \mathrm{mmHg}$ to the baseline systolic BP for the lower limbs. The data collected included patients' demographics, cuff pressure, cuff location, tourniquet duration and complication encountered among other parameters.

Results: A total of 160 procedures in 152 patients were included and analyzed using SPSS version 20.0. The prevalence rate of $1.9 \%$ for nerve palsy, $1.3 \%$ for tourniquet pain, $1.9 \%$ for surgical site infection and $5.6 \%$ for pressure sore were found in the study. No other complication was encountered.

Conclusions: From the results of this study, it is concluded that the use of pneumatic tourniquet under the prescribed conditions is associated with low prevalence of complications.
\end{abstract}

Keywords: Pneumatic tourniquet, Elective, Orthopaedic procedures, Complications

\section{INTRODUCTION}

A pneumatic tourniquet is a device with an inflatable cuff used to control venous or arterial circulation to an extremity for a period of time. Intelligent pneumatic tourniquets have mechanisms that monitor the cuff inflation duration as well as regulate the cuff pressure to a known pressure throughout the surgical procedure. ${ }^{1}$ They are also capable of testing the integrity of the tourniquet cuff, tubing, connectors, gauges and pressure source in about 30 seconds. ${ }^{1}$ The pneumatic tourniquets were introduced in 1904 by Havey Cushing. ${ }^{2}$ In the early 1980s, microprocessor-controlled pneumatic tourniquets were invented by Dr. James McEwen., ${ }^{3,4}$ Pneumatic tourniquet is one of the commonest forms of tourniquet used in orthopaedic practice in our hospitals today. ${ }^{5}$ Tourniquets are commonly used in limb surgeries. They allow surgical procedures to be performed with improved precision, safety and speed. Tourniquet safety is related to the pressure and duration of application which is 
directly proportional to the occurrence of complications. ${ }^{6}$ Modern pneumatic tourniquets have five basic components namely; an inflatable cuff, a compressed gas source, a pressure display, a pressure regulator and a connection tubing. ${ }^{1}$ Despite many advances in tourniquet technology, tourniquet-related injuries continue to be of concern. $^{2}$ Prior to the application of the tourniquet proximal to the surgical site, the limb is exsanguinated to drain away its contained blood either by elevation for 4 10 minutes or by serial compression of the limb from distal to proximal portion beyond the surgical site using Esmarch bandage. ${ }^{7}$ Customarily, before the exsanguination, prophylactic antibiotic is given if it is required for the surgery. ${ }^{7}$ This is necessary to allow the antibiotics to permeate the tissue before the exsanguination is done. The tourniquet is applied over the well-padded limb after the administration of the anaesthesia that will be used for the surgery. Tourniquet should be avoided in patients with deep vein thrombosis (DVT), peripheral neuropathies, peripheral vascular disease, diabetes mellitus and Raynaud's disease. ${ }^{1}$ Patient safety is the primary concern when working with a pneumatic tourniquet. ${ }^{8}$ It is important for the user to take time to become thoroughly familiar with the particular tourniquet he or she wants to use. Tourniquet use, although widespread in many fields of surgery, is not without complications. ${ }^{2}$ Injuries resulting from pneumatic tourniquet use are commonly pressure related and can also be caused by excessive tourniquet duration. ${ }^{8}$ Majority of these problems may be transient and even unnoticeable. However some are permanent or reversible only over extended period of time with prolonged disability being suffered by the afflicted person. Given the extent of potential complications, and even with guidance available to improve safety, some authors are seeking to remove ritual use of pneumatic tourniquet with a more conservative and selective approach. ${ }^{2,9-11}$ The most common complications of tourniquet use include; nerve injury, post tourniquet syndrome (pts), intraoperative bleeding, compartment pressure syndrome, pressure sores and chemical burns, toxic reactions, tourniquet pain, thermal damage to tissues, hyperthermia, rhabdomyolysis, metabolic changes and surgical site infection (SSI). Tourniquet pain is the most common complication seen in clinical practice. ${ }^{8}$ Therefore, the use of a pneumatic tourniquet to produce a bloodless surgical field places the patient at risk for complications. Certain patients because of their size, age or physical condition are more likely to respond unfavorably to pneumatic tourniquet use than others. ${ }^{8}$ Physicians are responsible for determining the correct cuff pressure and tourniquet time, but nurses share responsibilities for many of these measures. ${ }^{8}$ In addition, nurses assume responsibility for maintenance of the cuff and accessories. ${ }^{8}$

\section{METHODS}

The study was a prospective study over 18 month period (June 2014 to November 2015) at National Orthopaedic Hospital, Enugu. Following ethical approval and written informed consent, all patients undergoing elective orthopaedic procedure(s) under pneumatic tourniquet were consecutively recruited. The patients were clinically evaluated in the ward before being moved to theatre. The marked $\operatorname{limb}(\mathrm{s})$ for the proposed procedure(s) were thoroughly examined checking the integrity of the skin, the vascular status of the $\operatorname{limb}(\mathrm{s})$ and the presence or absence of any neuromuscular abnormality. The study was conducted using the 'intelligent pneumatic tourniquet, model: LT10010000, serial number 1005 manufactured by Medical Development and Engineering', Bhosari, India. The tourniquet application followed limb exsanguination by serial compression. The patients' baseline systolic blood pressures were measured just before induction of anaesthesia using the 'multiparameter patient monitor, model: BTL-08 manufactured by Ohmeda medical equipment', United Kingdom. The patients' body weights were measured with the 'Hana bathroom weighing scale, model: BR9011manufactured by the Big Boss Company, China' while their heights were measured with a 'metre rule'. The limb circumferences over the selected site of the cuff application were measured using 'butterfly brand measuring tape made in Shanghai China'. Cylindrical reusable regular single bladder type of tourniquet cuff of 3 different sizes $(61 \times 12 \mathrm{cms}, 48 \times 8 \mathrm{cms}$ and $30 \times 6.5 \mathrm{cms})$ depending on the measured limb circumference were used for the study. Intravenous ceftriaxone at doses of $1 \mathrm{~g}$ for adults and $50 \mathrm{mg} / \mathrm{kg}$ body weight for children were given as prophylaxis at the induction of anaesthesia at least 10 minutes before inflation of the cuff in all the cases. Adequate padding of limb at the site of the cuff application was done in all cases using wool roll as specified by the manufacturer. The tourniquet cuff was draped off the sterile surgical field using modern sterile impervious disposable drapes. The cuff pressure was determined by adding $100 \mathrm{mmHg}$ to the intra-operative baseline systolic blood pressure for the upper limb and $150 \mathrm{mmHg}$ to the intra-operative baseline systolic blood pressure for the lower limb as specified by the tourniquet manufacturer. The patients were monitored throughout the duration of the tourniquet application and removal. They were equally evaluated following tourniquet deflation at end of the procedure and then within 24 hours, at $5^{\text {th }}$ day, 6 weeks, 3 months and 6 months postoperatively. The complications were determined by clinical evaluations as well as using relevant laboratory investigations. Following tourniquet deflation at end of the procedure, the state of distal circulation was assessed by colour of the digits and capillary refill while the skin beneath the cuff assessed for presence of blisters and abrasions. The tourniquet duration was documented as displayed on the screen of the intelligent tourniquet machine. The wounds were inspected on the $5^{\text {th }}$ day postoperatively. The presence of pus was used as the diagnostic measure of SSI. Purulent materials from the wounds were sent for microscopy, culture and antibiotic sensitivity tests. The presence of motor paresis or paralysis and/or sensory loss in the limb was used as the diagnostic measure of nerve palsy. The presence of 
ischaemic skin necrosis or blisters was used to define pressure sore. Tourniquet pain was equally defined by the presence of persistent vague pain in the limb under the tourniquet within 30 minutes of cuff inflation despite adequate regional anaesthesia for the procedure and resolution of the pain on deflation of the cuff. The loss of up to $500 \mathrm{ml}$ of blood in adults and $10 \mathrm{ml} / \mathrm{kg}$ body weight in children was used to define increased intra-operative bleeding. The presence of scalding of the skin over the area of the cuff application was used to define chemical burn. The presence of paraesthesia, burning pain out of proportion to the surgical trauma worsened by passive stretching of the muscle group within the compartment and not relieved by analgesics as well as a firm wooden feeling on deep palpation was used as the diagnostic measure of compartment syndrome. The presence of persistent swelling, stiffness and pain in the hands or feet beyond 3 months after surgery was used as the diagnostic measure of post tourniquet syndrome. The inclusion criteria were all patients who had elective orthopaedic procedures of the extremities with the pneumatic tourniquet application as well as those whose pneumatic tourniquet application and removal was supervised directly by either the surgeon or the anaesthetist. Patients who had extremity surgeries with any other type of tourniquet apart from the pneumatic variety were excluded. The data collected included patients' demographics, the baseline intraoperative systolic blood pressure, the cuff pressure used, the cuff location, the cuff size, the limb operated, the limb circumference, type of procedure performed, type of anesthesia used, tourniquet duration, patient's body mass index (BMI), presence or absence of flabby skin, who supervised the application and removal of the tourniquet and complication(s) encountered. The data generated were coded, entered and analyzed using electronic computer software, statistical packages for social sciences (SPSS) version 20.0. Descriptive statistics which includes frequency, percent, mean, median, interquartile range and standard deviation were used to summarize categorical and continuous variables. Associations between categorical variables were analyzed using chi-square and logistic regression. Student's t-test was used to compare means of continuous variables.

\section{RESULTS}

A total of 160 procedures in 152 patients were included in the study and analyzed. Total of $138(86.3 \%)$ of the procedures were performed in the lower limbs. The tourniquet application and removal were supervised directly by the surgeon in $157(98.1 \%)$ of the procedures. The anaesthetists supervised the tourniquet application and removal in only 3 procedures performed under intravenous regional anaesthesia (IVRA). The median age of patients was 26.0 years with interquartile range of $11.3-45.0$.

Figure 1 shows slightly higher proportions were females $87(54 \%)$ with a male to female ratio of $1: 1.2$.

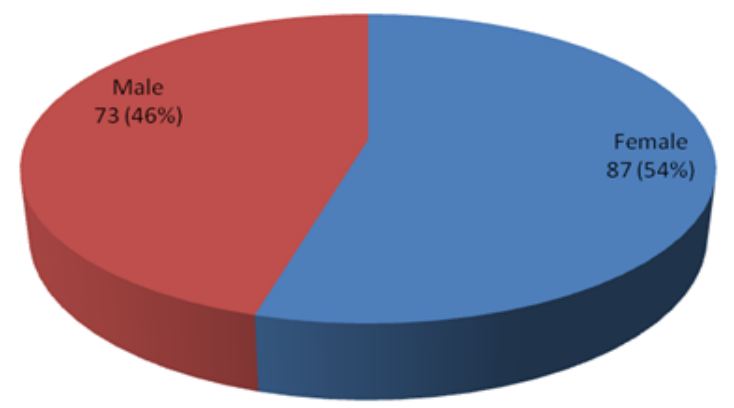

Figure 1: Sex distribution of the patients.

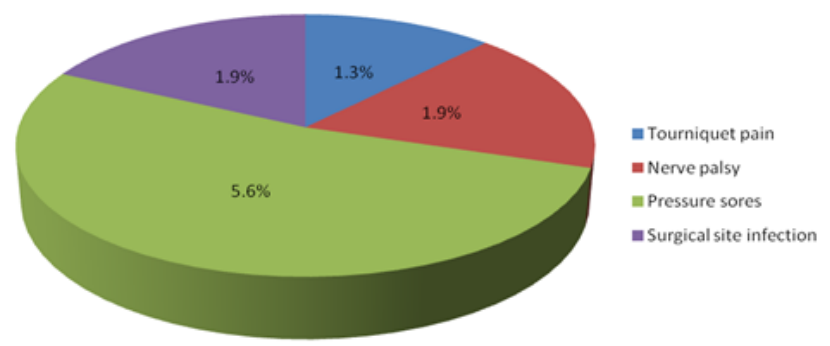

Figure 2: Prevalence of complications that follow use of pneumatic tourniquet.

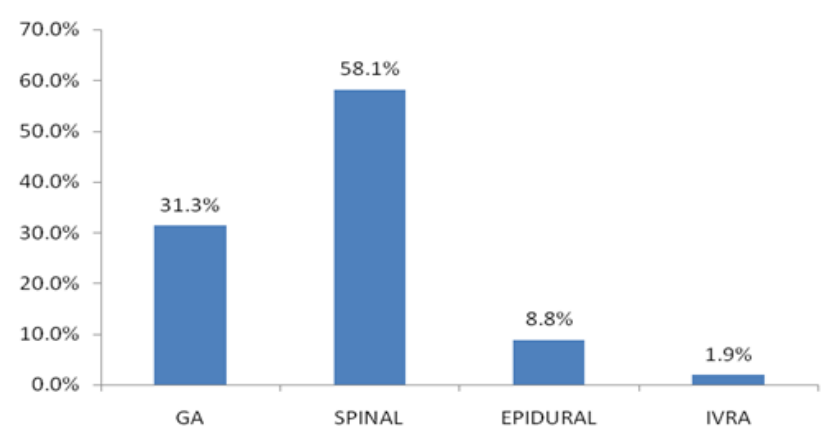

Figure 3: Types of anaesthesia used for the procedures.

Figure 2 shows that pressure sore over the skin beneath the site of the cuff application (5.6\%) is the most common complication.

Two out of the 3 nerve palsies occurred in the upper limb. Also 2 of the nerve palsies were completely resolved by the 3 months post-operative clinical evaluation while the remaining one resolved by the 6 months post-operative clinical evaluation. All the pressure sores occurred in the thigh beneath the site of application of the tourniquet cuff. They were all superficial pressure sores and were all resolved by the 6 weeks post-operative clinical evaluation. The 2 tourniquet pain also occurred in the thigh beneath the site of cuff application and both procedures were performed under spinal anaesthesia. All the 3 cases of surgical site infection found were on the leg for procedures performed on the tibia. In all the cases, the tourniquet cuff was applied on the thigh. The infections were all superficial surgical site infections and were all resolved by 6 weeks post-operative evaluation 
following antibiotics therapy, early suture removal and wound dressings using normal saline and povidone iodine solution. The organisms cultured from the wounds were Staphylococcus aureus in 2 cases and Klebisella species in one case. No polymicrobial isolates were found.

Figure 3 shows that majority of the procedures were performed under regional spinal anaesthesia (58.1\%). Table 1 show that the most common procedure performed under pneumatic tourniquet is corrective osteotomy of the tibia.
Table 2 show that cuff location was significantly associated with nerve palsy $(\mathrm{p}=0.036)$. Nerve palsy was 14 times more likely to occur on the arm than on the thigh $(\mathrm{OR}=13.700,95 \% \mathrm{CI}=1.187-158.107)$. However, obesity and cuff size were not significantly associated with nerve palsy $(p>0.05)$. Therefore the occurrence of nerve palsy was not dependent on obesity and cuff size. Similarly, pressure sore was not significantly associated with cuff location, obesity and cuff size $(p>0.05)$. Hence pressure sore is not determined by cuff location, obesity or cuff size.

Table 1: Types of procedures.

\begin{tabular}{|lll|}
\hline Procedures & Frequency & Percentage $(\%)$ \\
\hline Corrective osteotomy of tibia & 46 & 28.7 \\
\hline Internal fixation of tibia fracture & 37 & 23.0 \\
\hline Internal fixation of forearm bone(s) & 21 & 13.0 \\
\hline Achilles tendon elongation or repair & 14 & 8.8 \\
\hline Total knee arthroplasty & 14 & 8.8 \\
\hline Bone excision biopsy of tibia and fibula & 6 & 3.8 \\
\hline Knee joint exploration and ligament repair & 4 & 2.5 \\
\hline Ankle arthrodesis & 3 & 1.9 \\
\hline Implant removal from tibia and fibula & 3 & 1.9 \\
\hline Internal fixation of malleolar fracture(s) & 3 & 1.9 \\
\hline Knee arthroscopy & 3 & 1.9 \\
\hline Patellar fracture tension band wiring & 3 & 1.9 \\
\hline Open reduction and interposition arthroplasty of elbow joint & 2 \\
\hline Excision of gouty tophi in elbow and finger joints & 1 & 0.6 \\
\hline Total & 160 \\
\hline
\end{tabular}

Table 2: Association between cuff location, obesity, cuff size and complications.

\begin{tabular}{|c|c|c|c|c|c|}
\hline \multicolumn{3}{|c|}{ Nerve palsy } & \multirow{3}{*}{$\mathbf{P}$ value } & \multirow{3}{*}{ OR } & \multirow{3}{*}{$95 \% \mathrm{CI}$ for OR } \\
\hline & Yes & No & & & \\
\hline & $\mathrm{N}(\%)$ & $\mathrm{N}(\%)$ & & & \\
\hline \multicolumn{6}{|c|}{ Cuff location } \\
\hline Arm & $2(9.1)$ & $20(90.9)$ & 0.036 & 13.700 & $1.187-158.107$ \\
\hline Thigh & $1(0.7)$ & $137(99.3)$ & & & \\
\hline \multicolumn{6}{|l|}{ Obesity } \\
\hline Yes & $0(0.0)$ & $32(100.0)$ & 0.998 & 0.000 & $0.000-\mathrm{Nil}$ \\
\hline No & $3(2.3)$ & $125(97.7)$ & & & \\
\hline \multicolumn{6}{|l|}{ Cuff size } \\
\hline $30 \times 6.5 \mathrm{cms}$ & $6(100.0)$ & $0(0.0)$ & 0.387 & $\chi^{2}=1.897$ & \\
\hline $48 \times 8 \mathrm{cms}$ & $47(95.9)$ & $2(4.1)$ & & & \\
\hline $61 \times 12 \mathrm{cms}$ & $104(99.0)$ & $1(1.0)$ & & & \\
\hline \multicolumn{6}{|c|}{ Pressure sore } \\
\hline \multicolumn{6}{|c|}{ Cuff location } \\
\hline Arm & $0(0.0)$ & $22(100.0)$ & 0.998 & 0.000 & $0.000-\mathrm{Nil}$ \\
\hline Thigh & $9(6.5)$ & $129(93.5)$ & & & \\
\hline \multicolumn{6}{|l|}{ Obesity } \\
\hline Yes & $3(9.4)$ & $29(90.6)$ & & & \\
\hline No & $6(4.7)$ & $122(95.3)$ & & & \\
\hline \multicolumn{6}{|l|}{ Cuff size } \\
\hline $30 \times 6.5 \mathrm{cms}$ & $0(0.0)$ & $6(100.0)$ & .082 & $\chi^{2}=4.9950$ & \\
\hline $48 \times 8 \mathrm{cms}$ & $0(0.0)$ & $49(100.0)$ & & & \\
\hline $61 \times 12 \mathrm{cms}$ & $9(8.6)$ & $96(91.4)$ & & & \\
\hline
\end{tabular}


Table 3: Association between cuff location, obesity, cuff size and complications.

\begin{tabular}{|c|c|c|c|c|c|}
\hline & \multicolumn{2}{|c|}{ Surgical site infection } & \multirow{2}{*}{ P value } & \multirow{2}{*}{ OR } & \multirow{2}{*}{ 95\% C.I for OR } \\
\hline & Yes & No & & & \\
\hline & $\mathrm{N}(\%)$ & $\mathrm{N}(\%)$ & & & \\
\hline \multicolumn{6}{|c|}{ Cuff location } \\
\hline Arm & $0(0.0)$ & $22(100.0)$ & 0.998 & 0.000 & $0.000-\mathrm{Nil}$ \\
\hline Thigh & $3(2.2)$ & $135(97.8)$ & & & \\
\hline \multicolumn{6}{|l|}{ Obesity } \\
\hline Yes & $3(9.4)$ & $29(90.6)$ & 0.004 & 24.000 & $1.110-180.393$ \\
\hline No & $0(0.0)$ & $128(100.0)$ & & & \\
\hline \multicolumn{6}{|l|}{ Cuff size } \\
\hline $30 \times 6.5 \mathrm{cms}$ & $0(0.0)$ & $6(100.0)$ & 0.449 & $\chi^{2}=1.601$ & \\
\hline $48 \times 8 \mathrm{cms}$ & $0(0.0)$ & $49(100.0)$ & & & \\
\hline $61 \times 12 \mathrm{cms}$ & $3(2.9)$ & $102(97.1)$ & & & \\
\hline \multicolumn{6}{|c|}{ Tourniquet pain } \\
\hline \multicolumn{6}{|c|}{ Cuff location } \\
\hline Arm & $0(0.0)$ & $22(100.0)$ & 0.998 & 0.000 & $0.00-\mathrm{Nil}$ \\
\hline Thigh & $2(1.4)$ & $136(98.6)$ & & & \\
\hline \multicolumn{6}{|l|}{ Obesity } \\
\hline Yes & $0(0.0)$ & $32(100.0)$ & 0.998 & 0.000 & $0.000-\mathrm{Nil}$ \\
\hline No & $2(1.6)$ & $126(98.4)$ & & & \\
\hline \multicolumn{6}{|l|}{ Cuff size } \\
\hline $30 \times 6.5 \mathrm{cms}$ & $0(0.0)$ & $6(100.0)$ & 0.819 & $\chi^{2}=0.400$ & \\
\hline $48 \times 8 \mathrm{cms}$ & $1(2.0)$ & $48(98.0)$ & & & \\
\hline $61 \times 12 \mathrm{cms}$ & $1(1.0)$ & $104(99.0)$ & & & \\
\hline
\end{tabular}

Table 4: Mean comparisons of limb circumference, cuff pressure, tourniquet duration and BMI based on prevalence of nerve palsy.

\begin{tabular}{|lllcc|}
\hline & \multicolumn{2}{l}{ Nerve palsy } & & \\
& Mean \pm SD & Mean \pm SD & t value & P value \\
\hline Upper limb & Yes $(\mathrm{n}=2)$ & No $(\mathrm{n}=20)$ & & \\
\hline Cuff pressure $(\mathrm{mmHg})$ & $240.00 \pm 14.14$ & $248.00 \pm 41.75$ & 0.264 & 0.794 \\
\hline Limb circumference $(\mathrm{cm})$ & $32.50 \pm 2.12$ & $32.65 \pm 12.64$ & 0.016 & 0.987 \\
\hline Tourniquet duration $(\mathrm{min})$ & $124.00 \pm 8.49$ & $81.45 \pm 39.16$ & 1.501 & 0.149 \\
\hline BMI $\left(\mathrm{kg} / \mathrm{m}^{2}\right)$ & $24.43 \pm 5.87$ & $22.29 \pm 5.89$ & 0.492 & 0.628 \\
\hline Lower limb & Yes $(\mathrm{n}=1)$ & No $(\mathrm{n}=137)$ & & \\
\hline Cuff pressure $(\mathrm{mmHg})$ & 250.00 & $282.63 \pm 39.46$ & 0.824 & 0.412 \\
\hline Limb circumference $(\mathrm{cm})$ & 48.00 & $49.72 \pm 10.16$ & 0.168 & 0.867 \\
\hline Tourniquet duration $(\mathrm{min})$ & 130.00 & $103.38 \pm 43.24$ & 0.613 & 0.541 \\
\hline BMI $\left(\mathrm{kg} / \mathrm{m}^{2}\right)$ & 18.50 & $24.00 \pm 7.05$ & 0.778 & 0.438 \\
\hline
\end{tabular}

Table 3 shows that surgical site infection was significantly associated with obesity $(\mathrm{p}=0.004)$ but not with cuff location and cuff size $(p>0.05)$. Obese individuals were 24 times more likely to have surgical site infection $(\mathrm{OR}=24.000$, 95\% C.I=1.110-180.393); ( $p>0.05)$. However, no significant association was also found between cuff location, obesity, cuff size and tourniquet pain. Hence, tourniquet pain is not dependent on cuff location, obesity and cuff size.

In Table 4 although, the mean tourniquet duration (124.00 \pm 8.49 minutes) of patients with nerve palsy was higher than that of those without nerve palsy (78.22 \pm 28.66 minutes) in the upper limb but it was not statistically significant $(p>0.05)$. Similarly, that in lower limb was also not statistically significant $(\mathrm{p}>0.05)$.

Table 5 shows that patients with pressure sore have a significantly higher mean tourniquet duration (138.44 \pm 29.03 minutes) on the lower limb when compared to those without pressure sore $(101.14 \pm 42.99$ minutes $) \quad(p=0.012)$. Similarly, cuff pressures $(311.11 \pm 33.33 \mathrm{mmHg})$ were significantly higher among patients with pressure sore when compared with those without pressure sore $(280.39 \pm 39.14 \mathrm{mmHg}) ;(\mathrm{p}=0.023)$. 
Table 5: Mean comparisons of limb circumference, cuff pressure, tourniquet duration and BMI based on prevalence of pressure sore in lower limb.

\begin{tabular}{|lllll|}
\hline Parameters & $\begin{array}{l}\text { Pressure sore } \\
\text { Yes }(\mathrm{n}=9) \\
\text { Mean } \pm \text { SD }\end{array}$ & $\begin{array}{l}\text { No }(\mathrm{n}=129) \\
\text { Mean } \pm \text { SD }\end{array}$ & t value & P value \\
\hline Cuff pressure $(\mathbf{m m H g})$ & $311.11 \pm 33.33$ & $280.39 \pm 39.14$ & 2.295 & 0.023 \\
\hline Limb circumference $(\mathbf{c m})$ & $54.56 \pm 13.04$ & $49.36 \pm 9.87$ & 1.494 & 0.135 \\
\hline Tourniquet duration $(\mathbf{m i n})$ & $138.44 \pm 29.03$ & $101.14 \pm 42.99$ & 2.558 & 0.012 \\
\hline BMI $\left(\mathbf{k g} / \mathbf{m}^{2}\right)$ & $27.14 \pm 4.92$ & $23.74 \pm 7.12$ & 1.406 & 0.162 \\
\hline
\end{tabular}

Table 6: Mean comparisons of tourniquet duration and BMI based on prevalence of surgical site infection in lower limb.

\begin{tabular}{|c|c|c|c|c|}
\hline \multirow[b]{2}{*}{ Parameters } & \multicolumn{2}{|c|}{ Surgical site infection } & \multirow[b]{2}{*}{ t value } & \multirow[b]{2}{*}{$P$ value } \\
\hline & $\begin{array}{l}\text { Yes }(n=3) \\
\text { Mean } \pm S D\end{array}$ & $\begin{array}{l}\text { No }(n=135) \\
\text { Mean } \pm \text { SD }\end{array}$ & & \\
\hline Tourniquet duration (min) & $130.67 \pm 23.79$ & $102.97 \pm 43.33$ & 1.101 & 0.273 \\
\hline BMI $\left(\mathrm{kg} / \mathrm{m}^{2}\right)$ & $38.79 \pm 7.29$ & $23.63 \pm 6.69$ & 3.873 & $<0.001$ \\
\hline
\end{tabular}

Table 7: Association between type of anaesthesia and tourniquet pain.

\begin{tabular}{|lllll|}
\hline \multirow{2}{*}{ Types of anaesthesia } & Tourniquet pain & & $\chi^{2}$ value & P value \\
\hline Spinal & Yes N (\%) & No N $(\%)$ & 1.459 & 0.692 \\
\hline GA & $2(100.0)$ & $91(57.6)$ & & \\
\hline Epidural & $0(0.0)$ & $50(31.6)$ & & \\
\hline IVRA & $0(0.0)$ & $14(8.9)$ & & \\
\hline
\end{tabular}

Table 6 shows that patients with surgical site infection had a significantly higher BMI $\left(38.79 \pm .29 \mathrm{~kg} / \mathrm{m}^{2}\right)$ when compared to those without surgical site infection $(p<0.001)$. However, there is no statistically significant association between tourniquet duration and surgical site infection $(\mathrm{p}=0.273)$.

Table 7 shows that tourniquet pain was not significantly associated with the type of anaesthesia used $\left(\chi^{2}=1.459\right.$, $\mathrm{p}=0.692$ ).

Other complications such as increased intra-operative bleeding, chemical burns, post tourniquet syndrome, compartment syndrome and rhabdomyolysis were not encountered.

\section{DISCUSSION}

Although pneumatic tourniquets have improved safety, efficacy and reliability, their use can sometimes be accompanied by certain complications. Despite many advances in tourniquet technology, tourniquet-related injuries continue to be of concern to the orthopaedic surgeon. ${ }^{2,12-15}$ These complications are commonly pressure related and can also be caused by excessive tourniquet time. ${ }^{8,16,17}$ Noordin et al in their study noted that accurate monitoring and minimization of tourniquet duration was the most important factor in preventing adverse events. ${ }^{18}$ This study found prevalence of $1.9 \%$ for surgical site infection, $1.9 \%$ for nerve palsy, $1.3 \%$ for tourniquet pain and $5.6 \%$ for pressure sore. The surgical site infection rate of $1.9 \%$ found in the study was within the global wound infection rate of $1-5 \%$ in clean surgical wounds. ${ }^{5}$ However, it was lower than the already documented rate of $2-5.3 \%$ in our environment and the infection rate among the tourniquet group (6.3\%) found in the study done earlier in the hospital and University of Calabar Teaching Hospital by Udosen. ${ }^{5,19}$ It was also lower than the $10 \%$ documented by Salam et al. ${ }^{20}$ It was equally below the infection rate of $4 \%$ found by Enweani in his study among orthopaedic patients in Enugu. ${ }^{19}$ This may be attributable to the use of more modern synthetic disposable impermeable surgical drapes/gowns and use of more potent intravenous third generation cephalosporin antibiotic (ceftriaxone) for prophylaxis. However, it was slightly higher than $0.85 \%$ infection rate noted by Ogbemudia in his study at University of Benin Teaching Hospital. $^{4}$ This may be attributable to the fact that Ogbemudia used sterile cuff in his study whereas this study used reusable non-sterile cuff. Tissue ischaemia was identified by Salam et al as the principal factor upon which other factors operate to cause wound infection. ${ }^{20}$ This study found significant association between surgical site infection and obesity $(\mathrm{p}=0.004)$ as shown in Table 3. Obese patients were 24 times more likely to have surgical site infection than non-obese patients $(\mathrm{OR}=24.000,95 \%$ C.I=1.110-180.393). The tissue ischaemic factor identified by Salam et al may explain the reason for the 
occurrence of most of the SSI in the leg. ${ }^{20}$ All the 3 cases of SSI found in this study occurred in the leg following operations on the tibia which is mostly subcutaneous with very scanty soft tissue cover. This was also similar to the finding by Udosen where 4 out of the 5 infected wounds occurred in the tibia and gives credence to the problem of poor vascularity of anterior tibia. ${ }^{5}$ All the infections occurred within the first week of the postoperative period. This is similar to the finding by Udosen where 4 out of the 5 cases of SSI identified also occurred within the first week. However, this differs from the finding by Salam et al in their study where $50 \%$ of cases got infected during the third week. ${ }^{20}$ Nerve palsy was noted in 3 $(1.9 \%)$ of the cases studied. Two out of the 3 nerve palsies occurred in the upper limb. They were motor palsy of the radial and peroneal nerves without any sensory loss. It was also the only complication noted following the upper limb procedures. However, the study found no statistically significant difference between the mean tourniquet duration of patients that had nerve palsy (124.00 \pm 8.49 minutes) and those that did not have nerve palsy (78 \pm 28.66 minutes) following upper limb procedures $(\mathrm{p}=0.149)$. This may be attributable to the fact that intelligent pneumatic tourniquet was used for the study. This study also noted 14 times higher probability of occurrence of nerve palsy in the upper limb than the lower limb $(\mathrm{OR}=13.700$, 95\% $\mathrm{CI}=1.187-158.107)$. This also agrees with the finding by Middleton and Varian that reported 1 in 5000 and 1 in 13000 incidences for the upper and lower limbs respectively. ${ }^{21}$ However, the finding in this study differed from that by Udosen where he found no case of nerve palsy. This might be attributable to the fact that all the procedures performed in his study were in the lower limbs and the current study had a larger sample size. The finding of this study also differs from that reported by Odinsson et al in their study in Norway where only 3 out of the 15 nerve palsies found were in the arm while the remaining 12 were in the lower limb. ${ }^{13}$ Two out of the 3 cases of nerve palsies noted were completely resolved by the 3 months post-operative clinical evaluation while the $3^{\text {rd }}$ case resolved by the 6 months post-operative clinical evaluation. This shows that the injuries were transient loss of function and not irreversible nerve damage. This agrees with the finding of other researchers. ${ }^{13,17,22,23}$ The finding of only motor loss without sensory loss from nerve palsy in all affected patients in this study differs from that reported by Odinsson and Finsen who noted that one patient had complete sensory and motor palsy in the arm, 6 patients had only motor paresis while another 6 patients had only sensory disturbances. The spontaneous complete resolution of the nerve palsy in these 13 patients within 6 months of surgery is similar to that found in all the affected patients in the current study. ${ }^{13}$ The patient in their study that had complete sensory and motor loss in the upper limb had a tourniquet duration of 180 minutes at a pressure of $250 \mathrm{mmHg}$ which is also higher than the tourniquet duration of $124.00 \pm 8.49$ minutes at mean tourniquet pressure of $240.00 \pm 14.14 \mathrm{mmHg}$ noted in our study. These findings probably suggest that ischemia time is an important factor. ${ }^{6,13,24-27}$ The low prevalence of the nerve palsy noted in the study may also be attributable to strict adherence to the manufacturer's guideline on the use of the model of the intelligent pneumatic tourniquet, including the specified cuff pressures above the baseline intra-operative systolic blood pressure of the patient measured in theatre as well as avoidance of prolonged tourniquet duration. This agrees with the finding by Ogbemudia where no serious or long term complications occurred with tourniquet duration of between 120-150 minutes. ${ }^{4}$ Also the low prevalence of the nerve palsy may be equally attributable to the close and adequate supervision of the tourniquet application and removal by the surgeon in most of the cases $(98.1 \%)$ as well as monitoring of the patient throughout the duration of the procedures. The prevalence of pressure sore was found to be $5.6 \%$ in this study. It was the most common complication noted. This differed from the rate of $0.1 \%$ reported by Odinsson and Finsen in Norway. ${ }^{13}$ All the pressure sores occurred with the lower limb procedures in the thigh beneath the site of application of the cuff. The study noted that in the lower limb procedures, limb circumference $(58.63 \pm 4.93 \mathrm{~cm})$ and tourniquet duration (135.75 \pm 29.80 minutes) were significantly higher among patients that had pressure sore $(\mathrm{p}=0.011$ and 0.030 respectively). All the pressure sores were noted within 24 hours post-operative clinical evaluation. They were all superficial sores. All the pressure sores resolved completely by the 6 weeks post-operative clinical evaluation. The prevalence of tourniquet pain in the study was found to be $1.3 \%$. It was the complication with the lowest prevalence. This is in contrast to the documentation found in literature, tourniquet use and care which noted tourniquet pain as the most common complication seen in clinical practice. ${ }^{8}$ This difference may be attributable to the fact that pain has both subjective and objective components and its perception by an individual is influenced by many factors including physical and psychological factors. Also it is probable that most of the patients in the study were pre-occupied and carried away by the ultimate goal of getting their surgical problems treated thereby suppressing their pain perception. This agrees with that noted by Oragui et al in their review article that there is a complex etiology for tourniquet pain. ${ }^{28}$ They noted that the tolerance of the vague dull pain that may be experienced in the limb with tourniquet use depends upon a number of variables including patient pain threshold. ${ }^{28}$ Similarly, Ogufere et al noted an idiosyncratic relationship between pain perception and tourniquet use. ${ }^{29}$ The 2 cases of tourniquet pain occurred with the lower limb procedures at the thigh beneath the site of the cuff application despite adequate anaesthesia for the procedure. In both cases, the procedures were performed under regional spinal anaesthesia. This agreed with the documentation in literature that tourniquet pain may occur in patients receiving spinal or epidural anaesthesia. 8,30 When subjected to statistical analysis, tourniquet pain was not significantly associated with type of anaesthesia. 


\section{CONCLUSION}

The prevalence rate of $1.9 \%$ for surgical site infection, $1.9 \%$ for nerve palsy, $1.3 \%$ for tourniquet pain and $5.6 \%$ for pressure sore found in the current study is low and comparable with the findings of other studies. The use of pneumatic tourniquet under the prescribed conditions is associated with low prevalence of complications. Therefore, it is recommended for use in appropriate elective orthopaedic surgical procedures because it is safe. Similarly, the tourniquet duration should be kept less than 120 minutes to minimize the chances of any potential complication.

Funding: No funding sources Conflict of interest: None declared

Ethical approval: The study was approved by the institutional ethics committee

\section{REFERENCES}

1. Tourniquet. The Free Encyclopedia. Available at: http://www.en.wikipedia.org/ wiki/tourniquet. Accessed on 20 August 2019.

2. Murphy CG, Winter DC, Bouchier-Hayes DC. Tourniquet Injuries: Pathogenesis and Modalities for Attenuation. Acta Orthop Belg. 2005;71:635-45.

3. McEwen JA. US Patent, No.4,469,099. "Pneumatic Tourniquet". September 4, 1984.

4. McEwen JA. US Patent No 4,479,494. “Adaptive Pneumatic Tourniquet". October 30, 1984.

5. Udosen AM. The use of tourniquet in orthopaedic surgery: a prospective study of the effect of tourniquet use on incidence of postoperative wound infection. A dissertation submitted to the NPMCN. 1999: 1-34.

6. Ogbemudia AO. Composite sterile aneroid sphygmomanometer and rubber bandage tourniquet: indications, techniques and results. Internet $\mathrm{J}$ Orthopaed Surg. 2006;(2).

7. Reid HS, Camp RA, Jaco, WH. Tourniquet hemostasis: a clinical study. Clin Orthopaed. 1983;177:230-4.

8. Tourniquet Use and Care. Available AT: http://www.tourniquets.org. Accessed on 20 August 2019.

9. Braithwaite I, Klenerman L. Burns under the Tourniquet-Bruner's Ten Rules Revisited. J Med Dent Defence Union. 1996;12:14-5.

10. Carter KB, Shaw A, Telfer AB. Tourniquets for Surgery: Safety Aspects. J Med Eng Technol. 1983;7:136-9.

11. Jahss M. Disorders of the Foot and Ankle. Medical and Surgical Management. 2nd edition. Philadelphia: WB Saunders; 1991: 55-56.

12. Flatt AE. Tourniquet in Hand Surgery. Arch Surg. 1972;104:190-2.
13. Odinsson A, Finsen V. Tourniquet Use and Its Complications in Norway. J Bone Joint Surg [Br]. 2006;88:1090-2.

14. Bolton CF, McFarlane RM. Human Pneumatic Tourniquet Paralysis. Neurol. 1978;28:787-93.

15. Rorabeck CH, Kennedy JC. Tourniquet-Induced Nerve Ischaemia Complicating Knee Ligament Surgery. Am J Sports Med. 1980;8:98-102.

16. Saunders KC, Louis DL, Weingarden SI, Waylonis GW. Effect of Tourniquet Time on Postoperative Quadriceps Function. Clin Orthop. 1979;143:194-9.

17. Aho K, Sainio K, Kianta M, Varpanen E. Pneumatic Tourniquet Paralysis. Case Report. J Bone Joint Surg [Br]. 1983;65(4):441-3.

18. Noordin S, Mc Ewen JA, Kragh JF, Eisen A, Masri B. A. Surgical Tourniquets in Orthopaedics. J Bone Joint Surg Am. 2009;91:2958-67.

19. Enweani UN. Surgical Wound Sepsis in Clean Orthopaedic Procedures Bacteriology and Sensitivity in a Regional Specialist Centre. Oreint Journ Med. 1991;3(1):3-6.

20. Salam AA, Eyres KS, Cleary J, EL- Sayed H. The Use of Tourniquet when Plating Tibal Fractures. J Bone Joint Surg [Br]. 1991;73:86-7.

21. Middleton RWD, Varian JPW. Tourniquet Paralysis. Aust NZ Journ Surg. 1974;44:124-8.

22. Sunderland S. Nerves and Nerve Injuries. Edinburgh and London: E\&S Livingstone; 1968.

23. Speigel IJ, Lewin P. Tourniquet Paralysis. JAMA. 1945;129:432-5.

24. Chiu D, Wang HH, Blumenthal MR. Creatine Phosphokinase Release as a Measure of Tourniquet Effect on Skeletal Muscle. Arch Surg. 1976;111:714.

25. Heppenstall RB, Balderston R, Goodwin C. Pathophysiologic Effects Distal to a Tourniquet in the Dog. J Trauma. 1979;19:234-8.

26. Klenerman L. The Tourniquet in Operations on the Knee: A Review. J R Soc Med. 1982;75:31-2.

27. Klenerman L. Tourniquet Time- How Long? The Hand. 1980;12:231-4.

28. Oragui E, Parsons A, White T, Longo UG, Khan WS. Tourniquet Use in Upper Limb Surgery. Hand. 2011;6:165-73.

29. Ogufere WE, Giddins GEB, Thom JS. Upper Arm Tourniquet pain in Local Anaesthetic surgery. J Hand Surg. 1995;20:413-4.

30. Subspecialty Management, Complications of Orthopaedic Surgery. Available at: http://www. squ.edu.om//040404r00.htm. Accessed 20 August 2019.

Cite this article as: Ekwunife RT, Iyidobi EC, Enweani UM, Nwadinigwe CU, Okwesili CI, Ekwedigwe HC, et al. Assessment of complications following use of pneumatic tourniquet for elective orthopedic procedures at National Orthopedic Hospital, Enugu. Int J Res Orthop 2019;5:764-71. 